\title{
Interval between item repetitions and free recall memory ${ }^{1}$
}

THOMAS K. LANDAUER

STANFORD UNIVERSITY

The interval between two presentations of the same item has a marked effect on paired associate leaming (e.g., Greeno, 1964) but has been reported to have no effect on free recall (Waugh, 1963). To explore this apparent contradiction, a free recall experiment was performed with a mixed list of words and nonsense syllables in which the interval between two presentations of the same item was varied. A significant spacing effect was obtained for nonsense syllables but none for words. It is suggested that spacing may be important only for new associative or response integrative learning.

Waugh \& Norman (1965) and Waugh (1963) have reported that presenting a word for a second time essentially doubles the later probabllity of free recall of that word, independent of the interval between the two presentations. This result contrasts sharply with the case for paired associate learning. Several investigators have found that the value of a second presentation of a pair increases markedly as the interval between first and second presentation increases (Greeno, 1964; Landauer \& Rubin, 1966; Landauer \& Eldridge, 1967; Peterson, Wampler, Kirkpatrick, \& Salzman, 1963; Peterson, Hillner, \& Salzman, 1962). The present experiment was designed to replicate and explore further the repetition spacing effect or lack thereof in free recall. A straightforward experimental task was used in which Ss were presented with a set of verbal items, half of which were nonsense syllables and half adjectives. The Waugh and Norman result of no spacing effect was obtained for adjectives, but a clear spacing effect was observed for nonsense syllables.

\section{Method}

Sixty junior high school students participated as Ss on a voluntary basis. The Ss were shown a mixed list of common adjectives and high association value nonsense syllables, presented on cards at a 2 sec rate. They were instructed simply to observe the cards and try to remember for later recall the words and nonsense syllables which they had seen. The list was presented as the third task in a series of verbal learning tasks, the other two of which were concerned with entirely different problems and have been reported elsewhere (Landauer \& Eldridge, 1967). After tests on materials learned on the first two tasks in the series, approximately $7 \mathrm{~min}$ after initial presentation, self-paced free recall of the adjectives and nonsense syllables was elicited. The learning list was arranged so that various pairs occurred either once or twice with one of three intervals between the two presentations. One set of 10 items, five nonsense syllables and five adjectives, appeared once apiece. Another set of 10 items, five nonsense syllables and five adjectives, appeared twice each with no intervening items between the successive presentations. Another set of 10 items appeared twice each with three intervening items between successive presentations. Another set of 10 items appeared with 11 intervening times between the successive presentations. The remaining 10 items in the 80 item list were buffers, of which five appeared at the beginning and five at the end of the list. Some of the buffers also appeared a second time within the list as required for the list pattern. Four different list patterns meeting the spacing requirements were used. The particular words and nonsense syllables used were rotated through the spacing conditions.

Resulis

Table 1 gives the number of words recalled correctly for each of the repetition spacing conditions. For words there were no appreciable differences between any of the repetition interval conditions, and all occurred with essentially twice the probability of the single presentation items, in agreement with earlier findings (see above).

For nonsense syllables, however, there was a clear effect of interval. Repetitions with no intervening items differed significantly from repetitions with either three or 11 intervening items $(p<.01$ by binomial test), but not from single presentation. The three intervening item condition does not differ significantly from the 11 intervening item condition. These results resemble closely those found with paired associate learning.

Discussion

The lack of repetition interval effect reported by Waugh (1963) appears to be special not only to the case of free recall learning, but to only certain kinds of materials. The explanation for the lack of spacing

Table 1

Mean number of items recalled

\begin{tabular}{lcccc}
\hline & $\begin{array}{c}\text { Single } \\
\text { Presentation }\end{array}$ & $\begin{array}{c}\text { Intervening } \\
\text { ltems }\end{array}$ & $\begin{array}{c}3 \\
\text { Intervening } \\
\text { ltems }\end{array}$ & $\begin{array}{c}11 \\
\text { Intervening } \\
\text { ltems }\end{array}$ \\
\hline $\begin{array}{l}\text { WORDS } \\
\text { NONSENSE } \\
\text { SYLLABLES }\end{array}$ & .275 & .475 & .475 & .550 \\
\hline
\end{tabular}


effect in these special conditions is elusive. Previous results (referred to above) have abundantly shown that the intralist spacing effect holds for meaningful as well as nonsense materials in PA learning. Perhaps the difference lies in the requirement or nonrequirement of new "associative" learning. One might speculate that all forms of PA learning involve some associative learning, no matter what the materials, while free recall learning requires new association only as part of the integration of new response components, this being necessary only if the material consists of unfamiliar or nonsense words.

The hypothesis, then, is that spacing of repetitions is relevant only for new associative, including response integrative, learning. Perhaps, as has been previously suggested (e.g., Mandler, 1967), free recall of well known items involves some entirely different process, such as identification of appropriate "retrieval" rules, and is more akin to problem solving than to learning.

\section{References}

Greeno, J. G. Paired-associate learning with massed and distributed repetitions of items. J. exp. Psychol., 1964, 67, 286-295.

Landauer, T. K., \& Eldridge, Lynn. Effect of tests without feedback and presentation-test interval in paired-associate learning. $J$. exp. Psychol., in press.

Landauer, T. K., \& Rubin, Norma. Spacing of item repetition in paired-associate learning. Proc. 74th Annu. Conv. Amer. Psychol. Assoc., 1966, 91-92.

Mandler, G. Verbal learning. In New directions in psychology, III. New York: Holt, Rinehart \& Winston, 1967.

Peterson, L. R., Hillner, K., \& Salzman, D. Time between pairings and short term retention. J. exp. Psychol., 1962, 64, 550-551.

Peterson, L. R., Wampler, R., Kirkpatrick, M., \& Salzman, D. Effect of spacing presentations on retention of a paired-associate over short intervals. J. exp. Psychol., 1963, 66, 206-209.

Waugh, N. C. Immediate memory as a function of repetition. $J$. verbal Leam. verbal Behav., 1963, 2, 107-112.

Waugh, N. C., \& Norman, D. A. Primary memory. Psychol. Rev., $1965,72,89-104$

\section{Note}

1. I thank Lynn Eldridge for help in conducting the experiment. 